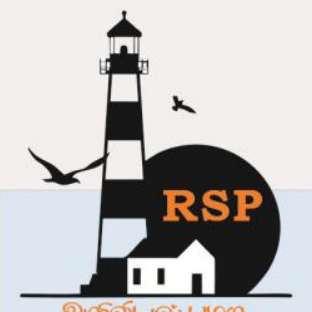

INTERNATIONAL RESEARCH JOURNAL ON ADVANCED SCIENCE HUB $582-4376$

Special Issue of First International Conference on Advancements in Management, Engineering and Technology (ICAMET 2020)

\title{
Grafting of Poly (acrylonitrile) on Cellulose to Synthesize and Characterize Potential Functional Polymers for Development of Metal Ion Sorbents
}

Dr Suresh Kumar

Associate Professor, Department of Chemistry,

Govt. P.G. College Una, Himachal Pradesh, 174303,Mobile: 09418945590

sureshchemistry2013@gmail.com

\begin{abstract}
Grafting of Acrylonitrile onto cellulose from different sources, using a variety of chemical initiators under various reaction conditions has been thoroughly investigated and reported. Hydrophobic nature of acrylonitrile hinders the partition of metal ions form aqueous phase thus narrows the applicationspectrum of its graft copolymers inseparation and enrichment processes. However, this drawback can be improved by post functionalization of nitrile (-CN) group to generate hydrophilic/ionic moieties by simple reactions like hydrolysis or substitution. In present study, acrylonitrile (AN) was grafted onto commercial cellulose to produce graft copolymers which can be used as starting materials for development of efficient metal ions sorbents. Grafting was carried out by redox initiation method using $\mathrm{Ce}^{+4}$ ions following the earlier reported scheme at the optimum grafting conditions worked out for grafting of AN onto cellulose ether, Hydroxyethyl cellulose(HEC). Graft copolymer thus obtained [hereafter called cell-g-poly (AN)] was characterized by Elemental analysis and FTIR. Both, cellulose and HEC belong to same back bone therefore, exhibited similar behaviour towards grafting. Percent grafting $\left(P_{g}=50\right)$ obtained in case of cellulose was in close agreement with $\left(P_{g}=55.5\right)$ that observed in case of HEC. Cell-g-poly (AN) served as useful precursor to develop reactive metal ion sorbing polymer supports as nitrile (-CN) moiety of poly (AN) is amenable to post functionalization and could be conveniently modified to targeted metal ion chelating amido-oxime group [poly $\left.\left(\mathrm{NH}_{2}-\mathrm{C}=\mathrm{NHOH}\right)\right)$ ] thus the resultant polymer could be used as a novel support for metal ion sorption.
\end{abstract}

Keywords: Polymeric support, graft co-polymer, homopolymer, post polymer reaction, percent grafting.

\section{Introduction}

Grafting is very common and convenient method for modification of properties by incorporation of desirable and targeted functionalities on the polymer backbone. A graft copolymer generally has side chains of some homopolymers. A monomer can be grafted as unitary or as binary system with other monomer(s).Graft copolymers are comb or brush shaped with graft chains as bristles and backbone as base where bristles are attached. Common methods of grafting are usually classified as induced by radiation source and induced by chemical initiation. Other less common methods are physical or mechanical treatment as thawing or beating of backbone polymer to induce active sites on backbone where grafting takes place. Grafting may proceed through ionic or free radical mechanism. In order to develop active metal ion sorbents, cellulose 
was first graft copolymerised with suitable monomers amenable to polymer analogous reactions. These graft copolymers served as precursors and can be conveniently post reacted to obtain polymers of desirable functionalities. Natural polymers like cellulose are finding increased use in low cost technologies for removal of metal ion from water bodies. These polymers are of renewable origin; environment friendly and offer highly cost effective technologies. Grafting of suitable monomers onto cellulose provides high degree of selectivity and offers a wide field to develop reactive graft copolymers for use as sorbents for water technologies. Cellulose extracted from pine needles is a new backbone polymer. Chauhan and co-workers have used it for the first time to synthesize large variety of functional polymers by grafting as single or from binary monomer mixtures. They have also developed cellulose based hydrogels, and reported these as supports for enzyme immobilization, flocculents and metal ion sorption[1-9].In present study an attempt has been made to report the synthesis of graft copolymers of acrylonitrile (AN) onto commercial cellulose backbone by redox initiation method using $\mathrm{Ce}+4$ ions (from ammonium ceric nitrate, $\mathrm{ACN}$ ). Both, cellulose and Hydroxyethyl cellulose (HEC) are similar backbones and are expected to exhibit similar chemical reactivity towards graftingthus grafting of AN was carried out following the earlier reported scheme at the optimum grafting conditions worked out for grafting of AN onto HEC[10].Graft copolymers were extracted in water to remove any traces of unreacted initiator and then in dimethyl formamide to ensure complete removal of homopolymer.Extraction process was repeated with fresh volume of extracting solvent till a constant weight was obtained. Graft copolymer thus obtained [hereafter called cell-g-poly (AN)] was characterized by Elemental analysis and FTIR. Cellg-poly (AN) served as useful precursor to develop reactive metal ion sorbing polymer supports. The nitrile moiety $(-\mathrm{CN})$ of poly (AN) is amenable to post functionalization and can be further converted to desired metal ion chelating amido-oxime function, poly $(\mathrm{NH} 2-\mathrm{C}=\mathrm{NHOH})[10]$.

\section{Experimental}

\subsection{Materials}

Acrylonitrile,Ammonium ceric nitrate $(\mathrm{ACN})$ and Cellulose (Merck, Germany) were used as they received.

\subsection{Method}

Graft copolymerization of acrylonitrile onto cellulose was carried out by redox initiation method using $\mathrm{Ce}+4$ ions. Cellulose (2g), ACN (6.59x10-2 moles/L), distilled water $(10.0 \mathrm{~mL})$ and acrylonitrile (3.792moles/L) were homogenized by stirring in a reaction vessel and reaction system was allowed to react at $700 \mathrm{C}$ for 30 minutes. After heating, grafted sample was first extracted in water to remove unreacted initiator, and then in dimethyl formamide (DMF) by stirring for $24 \mathrm{~h}$ to ensure complete removal of homopolymer. The extraction product was filtered and dried at $400 \mathrm{C}$ in an air oven. Extraction process was repeated to obtain a constant weight of the graft copolymer. The percent grafting $(\mathrm{Pg})$ was then evaluated using the relation reportedearlier [10-14].

\subsection{Characterization of Polymers}

Cellulose and cell-g-poly (AN) were characterized by FT-IR spectroscopy using $\mathrm{KBr}$ pallets on RKIN ELMER spectrophotometer. Grafted polymer was also analysed for $\mathrm{C}, \mathrm{H}$ and $\mathrm{N}$ content (recorded on Carlo ErbaEA-1108) to investigate structural aspects.

\section{Results and Discussions}

Grafting by redox systems usingtransition metal ions with variable oxidation states is extensively studied and used technique. To initiate grafting,metal ion may directly oxidise cellulose to form free radicals and small free radical species may be formed. Chain transfer reactions of free radicals can also induce grafting of cellulose backbone. The transition metal ions such as $\mathrm{Co}^{+3}$, $\mathrm{Mn}^{+3}, \mathrm{Fe}^{+3} \mathrm{Cr}^{+6}, \mathrm{~V}^{+5}$ and $\mathrm{Ce}^{+4}$, directly oxidise cellulose as a result of which free radicals sites are produced. Misra, et., al used metal chelates to induce grafting [11]. Amongst these, $\mathrm{Ce}^{+4}$ ions are successfully used for initiation of grafting by a number of co-workers [12-14]. Grafting possibly occurs at the hydroxyl groups present at positions 2 , 3 and 6 of anhydroglucose unit from where $\mathrm{H}$ abstraction is easier. 


\subsection{Graft Copolymerization of Acrylonitrile}

Acrylonitrile is a hydrophobic monomer and is expected to exhibit similar chemical reactivity towards grafting onto cellulose and its ether HEC. Thus the grafting of AN onto cellulose was carried out using $\mathrm{Ce}^{+4}$ ions following the earlier reported scheme at optimum grafting conditions [10],

(backbone $=2 \mathrm{~g}$, initiator $=6.59 \times 10^{-2}$ moles $/ \mathrm{L}$, monomer $=3.792$ moles $/ \mathrm{L}$, distilled water $=10$
$\mathrm{mL} ; \mathrm{P}_{\mathrm{g}}$ obtained $=55.5$ ) worked out for grafting of AN onto HEC. In present $\mathrm{s}$ tudy, $2 \mathrm{~g}$ cellulose afforded gravimetric value of $\mathrm{P}_{\mathrm{g}}=50$, when charged with 3.792 moles/L of $[\mathrm{AN}]$ and $6.59 \times 10^{-2}$ moles/L of $[\mathrm{ACN}]$ in $10 \mathrm{~mL}$ of water Percentage grafting $\left(\mathrm{P}_{\mathrm{g}}=50\right)$ of $\mathrm{AN}$ onto Was found to be very close to that of AN onto HEC $(\mathrm{Pg}=55.5)$ showing similar chemical behaviour of two backbones towards graft copolymerization.

Table.1 Elemental analysis of cell-g-poly (AN)

\begin{tabular}{|c|c|c|c|}
\hline \multirow[b]{2}{*}{ Polymer } & \multirow[b]{2}{*}{$P_{g}$} & Obs. & \multirow{2}{*}{$\begin{array}{l}\text { Calc. } \\
\% \mathrm{~N}\end{array}$} \\
\hline & & $\% \mathrm{C} \% \mathrm{H}$ & \\
\hline Cell-g-poly(AN) & 50 & \begin{tabular}{lll|}
28.78 & 5.81 & 8.71
\end{tabular} & 8.80 \\
\hline
\end{tabular}

Obs.= observed ,Calc.=calculated.

Table 3.2 FTIR analysis of Cellulose and Cell-g-poly (AN)

\begin{tabular}{|c|c|c|c|}
\hline$P_{g}$ & \multicolumn{3}{|c|}{ Vibration frequencies $\left(\mathrm{cm}^{-1}\right)$} \\
\hline & OH Str. & C-O-C Str./OH Ben. & $-\mathrm{C} \equiv \mathrm{NStr}$. \\
\hline \multicolumn{4}{|c|}{ Cellulose } \\
\hline-- & 3345.1 & $\begin{array}{l}1059.5 \\
1113.3 \\
1164.3 \\
1281.7 \\
1318.2 \\
1373.4 \\
1430.4\end{array}$ & -- \\
\hline \multicolumn{4}{|c|}{ Cell-g-poly(AN) } \\
\hline 64.6 & 3403 & $\begin{array}{c}1024 \\
1116 \\
1164.2 \\
1371.7 \\
1452.3\end{array}$ & 2243.2 \\
\hline
\end{tabular}

Str. $=$ Stretching, Ben.=Bending

\subsection{Characterization of Graft}

\section{Copolymerization of Acrylonitrile}

\subsubsection{Elemental analysis}

Evidence in support of grafting of $\mathrm{AN}$ onto cellulose was Obtained from $\% \mathrm{~N}$ content. Elemental analysis of cell-g-poly (AN) revealed

the presence of $28.28 \% \mathrm{C}, 5.81 \% \mathrm{H}$ and $8.71 \% \mathbf{N}$.
The observed $\% \mathrm{~N}$ in the grafted polymer when quantified corresponded to $49 \%$ incorporation of poly (AN) on to cellulose which was in close agreement with the gravimetric $\mathrm{P}_{\mathrm{g}}$ value of 50[10]. Results of elemental analysis of cell-gpoly (AN) are reported in Table.1.

\subsubsection{FT-IR analysis}

FTIR spectra of cellulose and cell-g-poly (AN) are given in Fig. 1 and 2 respectively and results are presented in Table.2. FTIR spectra of 
cellulose exhibited prominent peaks around $3345.1 \mathrm{~cm}^{-1}, 2899.9 \quad \mathrm{~cm}^{-1}, 1403.4 \mathrm{~cm}^{-1}, 1373.4 \mathrm{~cm}^{-}$ ${ }^{1} 1318.2 \mathrm{~cm}^{-1} 1281.7 \mathrm{~cm}^{-1} 1113.3 \mathrm{~cm}^{-1} 1059.5 \mathrm{~cm}^{-1}$ corresponding to $\mathrm{O}-\mathrm{H}, \mathrm{C}-\mathrm{H}$ stretching $\mathrm{O}-\mathrm{H}$ bending and $\mathrm{C}-\mathrm{O}-\mathrm{C}$ stretching respectively.In FTIR spectra of cell-g-poly (AN), besides the peaks due to stretching and bending of cellulose functionalities, additional peak at $2243.2 \mathrm{~cm}^{-1}$ due to $-\mathrm{C} \equiv$ Nstretchingof nitrile groups provided the evidence of grafting of acrylonitrile onto cellulose [10].

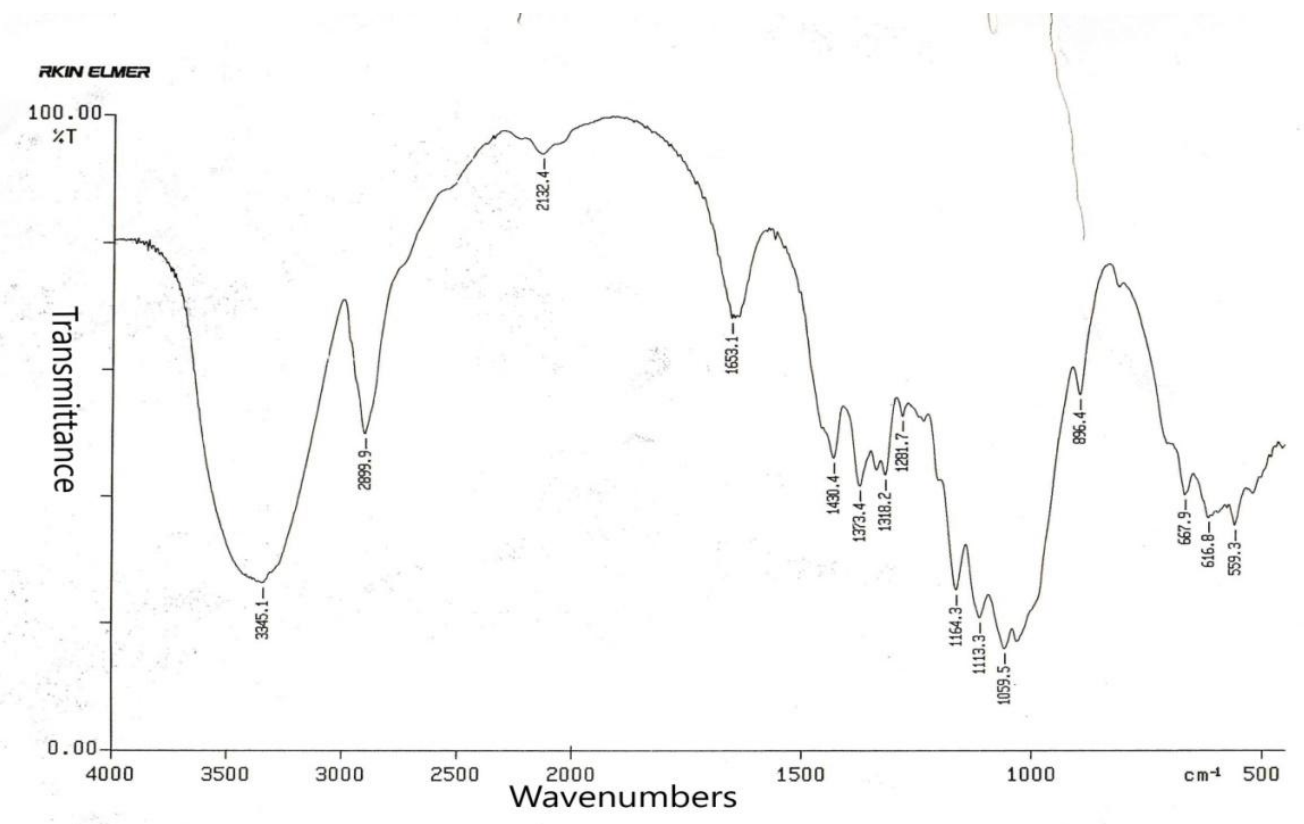

Fig: 1 FT-IR Spectrum of Cellulose



Fig: 2 FT-IR Spectrum of Cell-g-poly (AN) 


\section{Conclusions}

In present study acrylonitrile was successfully grafted on to cellulose using the scheme worked out for grafting of the same onto hydroxyl ethyl cellulose, and the grafted polymer thus produced could be functionalized and further used to generate poly (amido-oxime) chelating group by post polymer reactions of the later to develop polymer based metal ion sorbents. Both, cellulose and its ether HEC exhibited similar reactivity towards graft copolymerization affording comparable values of $\mathrm{P}_{\mathrm{g}}$ (cellulose $=50$, $\mathrm{HEC}=55.5$ ). Evidences of grafting were obtained from $\% \mathrm{~N}$ content in grafted sample and comparative analysis of FT-IR spectra of grafted and ungrafted cellulose.

\section{References}

[1].Chauhan, G. S., Misra, B.N., Kaur, I., Singha, A .S., \&Kaith, B.(1999). Ind.J.ofFibr. \&Text.Res.,24.269 .

[2].Chauhan, G.S., Bhatt, S.S., Kaur, I., Singha, A.S. \& Kaith,B.S. (2000). J.Polym.Mater, 17,336.

[3].Chauhan, G.S., Guleria, L.K. \&Mahajan, S. (2000).Desalination, 130, 85.

[4].Chauhan, G.S., Guleria, L.K. \&Mahajan, S. (2001).Desalination, 141, 235.

[5].Chauhan, G.S. and Mahajan, S. (2002).J Appl. Polym. Sci, 86, 468.

[6].Chauhan, G .S., Singh,B., Kumar,S. (2005).Journal of Applied Polymer Science, Vol. 98,373-382.

[7].Chauhan, G.S, Kumar,S., Verma,M. \& Sharma,R.(2005) .Polymers \& Polymer Composites, Vol. 13,No. 1.

[8].Chauhan, G.S., Bansal, M., Ram, B. \& Kaushik, A. (2018).International Journal of Biological Macromolecules,

[9].Chauhan, G., Jambal, H.S., Ranote,S.\&Kumar,D.(2020).

Separation and Purification Technology, 239:116513.

[10].Chauhan, G. S., Singh, B. \&Kumar, S. (2004). J.Polym.Mater., 21, 89-98.

[11].Misra.B.N.,Jassal,J.K.\&Dogra,R.(1981).J.M acromol.Sci.Chem.,A-16,1093.

[12].Erdelyi,J.andBorbely,S.E.(1981).
Papiripar,24,129; Chem.Abstr.,94,123359.

[13].Taga,T. and Inagaki,H.(1982)Sen'I

Gakkaishi,37,T516(1981);

Chem.Abstr.,96,37110u.

[14].El-ALfy,E.Khalil,M.I. \& Herbeish,A. (1981).J.Polym.Sci.,Polym.Chem.Ed.,19,313 7. 